\title{
Linkages among the challenges in mainstreaming climate change adaptation into local land use planning
}

\author{
S. C. Cuevas \\ University of Queensland, Australia
}

\begin{abstract}
Adaptation is a central issue in climate change research and crucial questions on the subject include the challenges that affect its operationalization at the local scale. However, information on how to examine these challenges and determine their characteristics is limited. Using a modified version of Ostrom's Institutional Analysis and Development framework, this paper addresses this gap through a case study in Albay, Philippines, with special interest on the challenges in mainstreaming climate change adaptation (CCA) into local land use plans. The paper developed 20 quantitative indicators to examine the nature of and linkages among these challenges. The mainstreaming indicators were computed using data gathered from a survey that incorporated a scorecard to quantify the respondents' answers; the survey was conducted among the key players in local land use planning in Albay. Correlation analysis showed that there are strong linkages between the challenges associated with local leadership, local government prioritization, and local government's commitment to CCA. Analysis of the mainstreaming indicator scores suggests that the challenges can obstruct mainstreaming of CCA at varying degrees of severity; when overcome, they become significant opportunities for the effective operationalization of the approach. The paper offers analytical tools that have the potential to help planners make informed decisions concerning the challenges in mainstreaming CCA, and formulate practical strategies for its implementation.

Keywords: modified IAD framework, mainstreaming indicators, mainstreaming challenges, local government prioritization, local leadership, commitment to climate change adaptation.
\end{abstract}




\section{Introduction}

Understanding the barriers to climate change adaptation (CCA) has never been more important than the present, when adaptation focus is shifting from determining whether there is a need to adapt, to how to adapt $[1,2]$. Thus, scholars have been expanding the knowledge base on the subject to fully comprehend the adaptation process [3]. Consequently, the topic on the barriers to adaptation has created its own niche in adaptation research [1, 4-6].

This paper contributes to CCA research by advancing the discussion on the linkages and interdependencies among the barriers to adaptation, through a case study on mainstreaming CCA into the local land use planning in Albay, Philippines. Mainstreaming is an adaptation approach that integrates climate change concerns into development planning, policy and decision-making processes and procedures $[7,8]$. It synergizes CCA and development goals and agenda, thus, is gaining popularity especially in developing countries [9]. Consequently, understanding the nature of the barriers to mainstreaming CCA would be a substantial undertaking to ensure effective operationalization of the approach.

The paper continues with a brief discussion of the interconnections among barriers to adaptation. Afterwards, a background on the climate change concerns in the Philippines is presented. Next, the four-stage mixed methodology the research devised to examine the case study is discussed. This includes: (1) how the Institutional Analysis and Development (IAD) framework was modified to suit the analytical needs of this CCA research (IAD-CCA); and (2) how the mainstreaming indicators were developed. The results of the correlation analysis and the computed values of the mainstreaming indicators are then examined, along with some qualitative analysis on the data. This paper concludes that: (1) mainstreaming challenges are liked to each other; (2) at the city/municipal level, there are strong linkages among local leadership, local government prioritization and the local government's commitment to CCA in relation to mainstreaming CCA; and (3) a challenge can be a significant barrier or opportunity to another challenge.

\section{Barriers to adaptation}

Among the critical questions in adaptation research pertain to the barriers obstructing, delaying, diverting or blocking the adaptation process [1]. A number of studies: (1) identified these barriers; (2) determined their nature and origin; and (3) investigated the conditions encompassing the barriers, among others $[5,6,10$, 11]. Still, more information is needed to fully understand the complexities in overcoming these barriers and effectively operationalizing an adaptation measure; such information includes how these barriers are interconnected $[6,12]$.

Literature suggests that the barriers are linked to each other. For example, the lack of awareness and knowledge of climate change issues is a significant barrier to adaptation [13]. With no understanding of the climate risks, local leaders tend to prioritize climate change the least [14]. Accordingly, the lack of local leadership 
that supports CCA can significantly impede implementation of CCA measures [3, 10]. Without this leadership, it is likely that financial, as well as community, support for adaptation activities will be also scarce $[5,6,12]$. The lack of funds, in turn, can limit the human resources that focus on adaptation initiatives [13]. Meanwhile, the absence of community support indicates people's lack of willingness to accept and abide by the rules and regulations related to CCA [5, $10]$.

Thus, some barriers to adaptation are interdependent; though their interdependencies differ in degrees and intensities [6]. Essentially, it is not sufficient to just identify the barriers to adaptation; it is equally important to understand their linkages to one another [11]. Knowledge on how the barriers are interconnected can aid in designing strategies on how to overcome these barriers. Such is the aim of the case study conducted in the province of Albay, Philippines.

\section{Climate change impacts in the Philippines}

The Philippines is a developing country in Southeast Asia with 92.3 million people as of census 2010 [15]. It is visited by an average of 20 typhoons a year and is considered as the world's third most vulnerable country to extreme weather events (i.e. typhoons) $[16,17]$. Of late, the country has been experiencing intensified typhoons due to climate change [18]. Consequently, the Philippines is particularly vulnerable to present and future climate risks [16]. This notion was proven when typhoon Yolanda (international name: Haiyan) - the most powerful typhoon in recent history - struck the Philippines in November 2013 [19]. Impacts of Typhoon Yolanda included: 6,300 people dead; 28,689, injured; and 1,061 people missing. It distressed around 16 million people; damages were assessed at PHP 89.6 billion (USD 2.1 billion) [20].

Early on, the Philippines has recognized the need to adapt to climate change. Thus, in 2009, it enacted the Climate Change Act (Republic Act (RA) 9729), a law that institutionalized mainstreaming of climate change into the government policymaking, planning, and decision-making processes. A year later, it passed the Disaster Risk Reduction and Management Act (RA 10121), a legislation that mandated for mainstreaming of CCA and disaster risk reduction (DRR) (i.e. CCADRR) into the development decision-making and planning processes of both the national and local governments units' (LGUs). In 2011, the People's Survival Fund (RA 10174) was institutionalized to provide a long-term financial stream for CCA.

The local government units (LGUs) in the Philippines are composed of provinces, cities, and municipalities (towns). A province is the main local political unit comprising of municipalities and cities [21]. Among the LGUs in the Philippines, Albay province is among the most active in advancing local CCADRR initiatives because of its high vulnerability to climate-related disasters [16, 22]. To adapt and build communities resilient to climate change, the Provincial Government of Albay has implemented some of the best CCA-DRR practices (i.e. local CCA-DRR policies, projects, and programs) in the country [22]. In fact, the "Albay Declaration on Climate Change Adaptation" initiative in 2007 was key to 
the enactment of the Climate Change Act [23]. Accordingly, the Albay experience is expected to bring robust information relating to local mainstreaming efforts.

\section{Methodology}

This section presents the four-stage mixed methodology devised to investigate the challenges in mainstreaming CCA into Albay's local land use planning process (Figure 1). This study's fundamental analytical tool was Ostrom's [24] Institutional Analysis and Development (IAD) framework. Mainstreaming CCA is essentially an institutional concern, thus, should be analyzed under the institutional lens $[9,25]$. Still, the IAD needed to be modified to accommodate some specific needs of the research. Changes were applied in Stage 1.

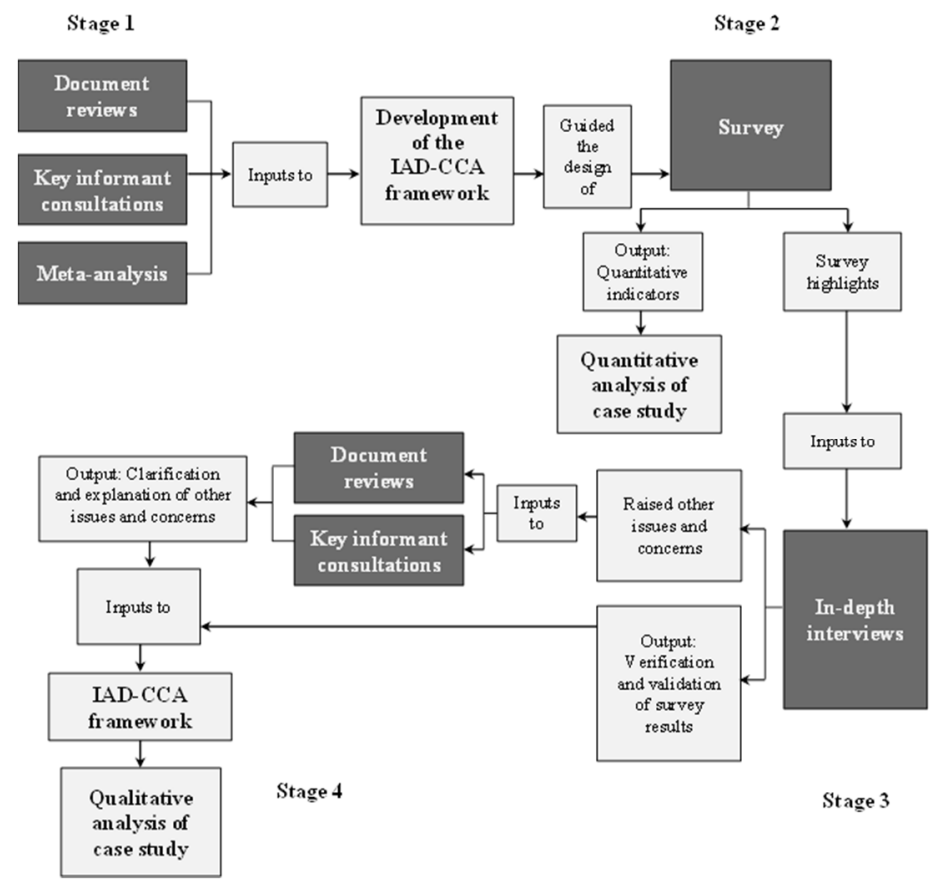

Figure 1: Four-stage mixed methodology flow chart [26].

The IAD has five fundamental elements, namely: (1) the action arena, the central variable where institutional settings are analyzed; (2) the exogenous variables (i.e. biophysical conditions, community attributes, and rules-in-use) that affect the action arena; (3) the patterns of interaction generated by the actors and institutional arrangements in the action arena; (4) the outcomes resulting from these patterns of interaction; and (5) the evaluation criteria that guide how the patterns of interactions and outcomes are examined [24, 27].

In this study, the institutional arrangements in the land use planning system and the actors who follow these arrangements were analysed in the action arena. 
Critical to this analysis were the evaluation criteria of the IAD, as they determined how the patterns of interaction and their outcomes were examined. Hence, following the examples of Rudd [28], Ratner et al. [29] and Jones et al. [30], the study modified the evaluation criteria to make them more effective in the analysis. Specifically, the evaluation criteria were substituted with factors that affect the effective on-the-ground application of the mainstreaming endeavour (i.e. 20 mainstreaming challenges). The mainstreaming challenges were identified through an extensive range of adaptation literature on: (1) the barriers, constraints, and obstacles to CCA and mainstreaming CCA; and (2) the drivers or enablers of adaptation $[4,6,10,13,14,31,32]$. Consultations with key informants confirmed the relevance of these challenges. The challenges were spread across three main classifications, namely information, institutional, and resource capacity groups. Consequently, the IAD was transformed into the IAD framework as applied to mainstreaming CCA research (IAD-CCA) (Figure 2).

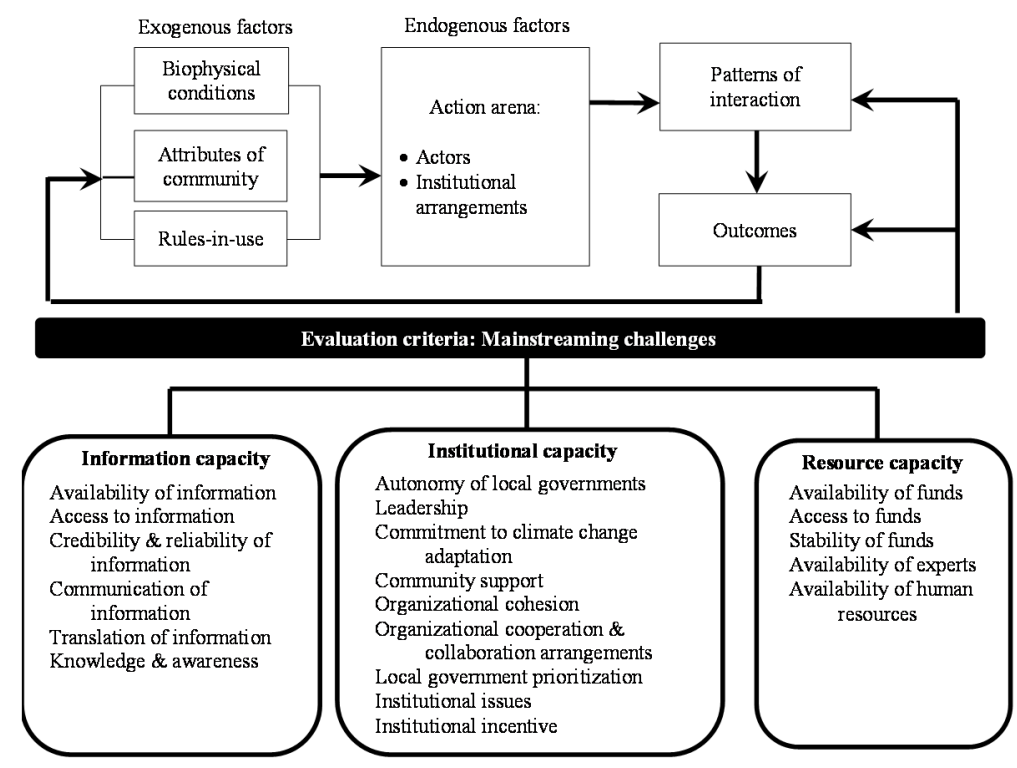

Figure 2: Institutional Analysis and Development framework for mainstreaming climate change adaptation (IAD-CCA) [26].

The IAD-CCA framework guided the designs of the succeeding stages in the methodology. In particular, the queries in the survey, conducted in Stage 2, were patterned from the 20 mainstreaming challenges of the IAD-CCA evaluation criteria. Using a purposive sampling technique, the survey was conducted among the key members of the local land use planning system in Albay. Particularly, the respondents were representatives of institutions involved in the actual preparation, review and approval of the local land use plans in Albay and its two LGUs (i.e. Legazpi city and Camalig municipality). Snowball sampling was applied for additional survey respondents (Table 1). 
Table 1: List of survey/interview respondents.

\begin{tabular}{|l|l|}
\hline Scale & Representative/Institution \\
\hline \multirow{4}{*}{ Legazpi City (4) } & City Development Council (City Mayor's Office) \\
\cline { 2 - 2 } & Legazpi City Planning Development Office \\
\cline { 2 - 2 } & $\begin{array}{l}\text { Legazpi City Disaster Risk Reduction Management } \\
\text { Council }\end{array}$ \\
\hline \multirow{5}{*}{$\begin{array}{l}\text { Provincial Land Use } \\
\text { Committee Members (11) }\end{array}$} & Camalig Planning Development Office \\
\cline { 2 - 2 } & Camalig Disaster Risk Reduction and Management Officer \\
\hline & Provincial Planning and Development Office \\
\cline { 2 - 2 } & Pousing and Land Use Regulatory Board \\
\cline { 2 - 2 } & Department of Interior and Local Government \\
\cline { 2 - 2 } & Department of Environment and Natural Resources \\
\cline { 2 - 2 } & Elbay Public Safety and Emergency Management Office \\
\hline & Mines and Geosciences Bureau \\
\hline
\end{tabular}

Note: Numbers in the "Scale" column represent the number of respondents.

Scorecards were incorporated in the survey queries to quantify the answers of the respondents. Specifically, each question had 3 answer choices that described the conditions surrounding the mainstreaming challenges; a respondent gave either 1 (worst condition), 2 (moderate condition), or 3 (best condition) score on a query. As a result, quantitative indicators (i.e. mainstreaming indicators) that had values between $1 \leq \mathrm{n} \leq 3$ were developed. The answers of all the respondents were given equal weights. Meanwhile, Cronbach's alpha statistics were computed to test for the reliability of the indicator estimates.

The mainstreaming indicator scores then directed the flow of discussion during semi-structured in-depth interviews in Stage 3; line of questions focused on the indicators with scores closest to either 1 or 3 . Interviews were conducted among the same set of survey respondents. In effect, results from the interviews confirmed and supported the mainstreaming indicator scores. However, the interviews also raised additional issues and concerns regarding the mainstreaming process. These (issues and concerns) were clarified in Stage 4 through document reviews and consultations with key informants. Afterwards, all the information gathered were analyzed based on the IAD-CCA framework structure (i.e. patterns of interaction and outcomes examined through the evaluation criteria). Fundamentally, the complete methodology allowed for both quantitative and qualitative assessments on the case study.

\section{Mainstreaming challenges: linkages and state-of-play}

This section presents the results of the pair-wise correlation analysis on the survey data, by provincial and city/municipal levels, as well as the interpretations of the computed mainstreaming indicator scores. 


\subsection{Correlation among the mainstreaming challenges}

Correlation coefficients describe the degree of relationships between two variables. A coefficient equal to $1(-1)$ signifies a perfect direct (inverse) relationship, while a coefficient equal to zero implies no relationship (Moutinho [34]). In this section, analysis was limited to the mainstreaming challenges with correlations $\geq 0.7$ (i.e. high correlations or strong association).

Relatively high frequencies of strong linkages between resource capacity challenges and the other challenges were observed. To illustrate, at the provincial scale, stability of funds and access to funds each had strong relationships with seven other challenges; availability of experts with four; and availability of resources and availability of funds were each strongly linked to two other challenges. On the other hand, local government prioritization and institutional incentives were each strongly connected to three other challenges; while the translation of information, credibility and reliability of information, and knowledge and awareness challenges were each strongly associated to two others. Community support was only strongly linked to local government prioritization. This trend was observed also at the city/municipal scale, though it was less pronounced (Tables 2 and 3).

This set of information can be used in designing schemes for mainstreaming CCA. For example, to affect an extensive list of challenges, strategies focused on improving access to resources can be devised. A similar effect may also be possible by raising the availability of experts. However, using correlation results in making decisions should be done with caution and be supported by other sets of data and evidence. This is because although correlation suggests association between variables, it does not explain causation [34].

Another noteworthy observation was the tripartite linkages among local leadership, commitment to CCA and local government prioritization challenges at the city/municipal scale (Table 3). Local leadership pertains to the existence of a climate change champion in the locality, while local government prioritization denotes the extent by which the CCA is prioritized by the local government. Lastly, commitment to CCA relates to the (non)existence of a legislative framework for local adaptation. This tripartite relationship suggests that addressing one challenge will affect the other two, and vice-versa. Also, the action to overcome one (challenge) can be magnified by the possible ripple effects of the other two (challenges) on the rest of the mainstreaming challenges. This notion is confirmed and further explored in the next section.

\subsection{How do the challenges affect mainstreaming of climate change adaptation?}

Computing for the Cronbach's alpha statistics is a common method of measuring the reliability of estimates for indices; the accepted values of alpha vary between 0.70 to 0.95 [35]. Cronbach's alpha statistics for the provincial and city/municipal datasets registered at 0.9487 and 0.9001 , respectively, suggesting reliable estimates for the mainstreaming indicator scores. 
Table 2: Mainstreaming indicators with correlation $>0.70$, provincial level.

\begin{tabular}{|l|l|l|}
\hline Mainstreaming indicator & Score & Mainstreaming indicator \\
\hline Translation of information & $0.753^{*}$ & Credibility and reliability of information \\
\hline Local government prioritization & $0.725^{*}$ & Community support \\
\hline Institutional incentive & $0.776^{*}$ & Translation of information \\
\hline \multirow{4}{*}{ Access to funds } & $0.709^{*}$ & Knowledge and awareness \\
\cline { 2 - 3 } & $0.745^{*}$ & Local government prioritization \\
\cline { 2 - 3 } & $0.815^{*}$ & Institutional incentive \\
\cline { 2 - 3 } & $0.899^{*}$ & Availability of funds \\
\hline \multirow{5}{*}{ Stability of funds } & $0.740^{*}$ & Credibility and reliability of information \\
\cline { 2 - 3 } & $0.745^{*}$ & Knowledge and awareness \\
\cline { 2 - 3 } & $0.847^{*}$ & Institutional incentive \\
\cline { 2 - 3 } & $0.907^{*}$ & Availability of funds \\
\cline { 2 - 3 } & $0.899^{*}$ & Access to funds \\
\hline \multirow{5}{*}{ Availability of experts } & $0.745^{*}$ & Local government prioritization \\
\cline { 2 - 3 } & $0.765^{*}$ & Institutional incentive \\
\cline { 2 - 3 } & $0.899^{*}$ & Access to funds \\
\cline { 2 - 3 } & $0.706^{*}$ & Stability of funds \\
\hline \multirow{2}{*}{ Availability of human resources } & $0.860^{*}$ & Access to funds \\
\cline { 2 - 3 } & $0.713^{*}$ & Stability of funds \\
\hline
\end{tabular}

*Specifies the significance level of correlation coefficients at the 5\% level or better (i.e. $95 \%$ confidence level).

Table 3: Mainstreaming indicators with correlation $>0.70$, city/municipal level.

\begin{tabular}{|l|l|l|}
\hline Mainstreaming indicator & Score & Mainstreaming indicator \\
\hline Translation of information & 0.750 & Communication of information \\
\hline Organizational cohesion & $1.000^{*}$ & Access to information \\
\hline Organizational cooperation arrangements & $1.000^{*}$ & Availability of information \\
\hline Commitment to CCA & 0.750 & Leadership \\
\hline \multirow{2}{*}{ Local government prioritization } & $1.000^{*}$ & Leadership \\
\cline { 2 - 3 } & 0.750 & Commitment to CCA \\
\hline Institutional incentive & $0.917^{*}$ & Knowledge and awareness \\
\hline Availability of funds & -0.750 & Translation of information \\
\hline \multirow{3}{*}{ Access to funds } & -0.750 & Translation of information \\
\cline { 2 - 3 } & $1.000^{*}$ & Availability of funds \\
\hline \multirow{4}{*}{ Availability of experts } & 0.730 & Communication of information \\
\cline { 2 - 3 } & 0.710 & Knowledge and awareness \\
\cline { 2 - 3 } & 0.730 & Leadership component \\
\cline { 2 - 3 } Availability of human resources & 0.730 & Local government prioritization \\
\hline & 0.750 & Availability of funds \\
\cline { 2 - 3 } & 0.750 & Access to funds \\
\cline { 2 - 3 } & 0.730 & Stability of funds \\
\hline
\end{tabular}

*Specifies the significance level of correlation coefficients at the $5 \%$ level or better (i.e., $95 \%$ confidence level).

Note: CCA - climate change adaptation. 
The indicator scores reflected the conditions encompassing the mainstreaming challenges at the provincial and city/municipal scales. The interviews justified the scores and revealed an interesting characteristic of the mainstreaming challenges. That is, the challenges exist in varying levels that depict the degrees of their impacts on the mainstreaming process. To illustrate, indicators with scores of 1.0 $\leq \mathrm{n}<2.0$ comprise the first level or the primary barriers; $2.0 \leq \mathrm{n}<2.25$, second level barriers; $2.25 \leq \mathrm{n}<2.5$ third level barriers; and scores of $\geq 2.5$ composed the fourth-level or those challenges that have been overcome and have become opportunities for mainstreaming.

Continuing with the discussion from the last section, the leadership indicator was considered as an opportunity in Albay because of the existence of a climate change champion (i.e. Provincial Governor Jose Salceda, the chief executive officer of Albay) (Table 4). The actions and initiatives of Governor Salceda on CCA matters were recognized not only within the Philippines, but in the international community as well. Thus, he was acknowledged by the United Nations International Strategy for Disaster Reduction as a "Senior Champion" of CCA and DRR in 2010 and one of the "Champion for Making Cities Resilient" $[36,37]$.

Table 4: List of selected opportunities for mainstreaming in Albay.

\begin{tabular}{|l|c|c|}
\hline Mainstreaming indicator & Provincial & City/Municipal \\
\hline Knowledge and awareness & 2.70 & 2.69 \\
\hline Leadership & 2.67 & 2.57 \\
\hline Commitment to climate change adaptation & 2.71 & 2.43 \\
\hline Community support & 2.58 & 2.70 \\
\hline Local government prioritization & 2.77 & 2.57 \\
\hline Institutional incentive & 2.81 & 2.86 \\
\hline
\end{tabular}

Under the leadership of Governor Salceda, the Provincial Government of Albay enacted local legislations that institutionalized CCA as a local government priority $[16,38]$. Such legislative framework for CCA in Albay established a local government committed to CCA. Accordingly, the local government prioritization and commitment to CCA indicators were assessed as opportunities in the province (Table 4). In addition, all the respondents assessed the planners and decisionmakers in Albay to have knowledge and awareness on climate change issues; they attributed this to the influence of the climate change champion. The increased understanding of the climate risks and the benefits from CCA, in turn, incentivized the planners and decision-makers to apply the mainstreaming approach [39]. Meanwhile, the combination of all the CCA efforts gained the support of the community, as reflected in the participation of the community members on the CCA-related activities, programs, and projects [23]. Thus, as the correlation analysis suggested, local leadership did have a strong linkage with the other mainstreaming challenges. As an opportunity, local leadership was key in overcoming the other challenges in local mainstreaming of CCA. 


\section{Conclusion}

In this paper, mainstreaming challenges are the factors that affect or influence the effective operationalization of the mainstreaming measure. They can either be barriers, when they impede the effectively operationalization of mainstreaming, or opportunities, when they have been overcome and have positive effects on the other challenges. The study devised a four-stage mixed methodology that classified these mainstreaming challenges into three capacity groupings institutional, information, and resource. Through this methodology, quantitative data were collected, allowing correlation analysis to be conducted. Furthermore, quantitative mainstreaming indicators that can assess a challenge's degree of impact on the mainstreaming process were also developed. Thus, the paper offers analytical tools that have the potential to help planners make informed decisions concerning the challenges in mainstreaming CCA.

More importantly, the paper provided empirical evidence on the direct linkages among the mainstreaming challenges. It showed that these linkages can exist at varying degrees (i.e. strong) and different forms (i.e. tripartite relationships). These sets of information can help planners and decision-makers formulate practical strategies for operationalizing CCA mainstreaming and other adaptation measures and approaches.

\section{Acknowledgement}

The author is grateful for the support of the CSIRO-UQ INRM PhD Scholarship.

\section{References}

[1] Ekstrom, J.A., Moser, S.C., \& Torn, M., Barriers to climate adaptation: A diagnostic framework. California Energy Commission: USA, 2011.

[2] Biesbroek, G.R., Klostermann, J., Termeer, C. \& Kabat, P., On the nature of barriers to climate change adaptation. Regional Environmental Change, 13, pp. 1119-1129, 2013.

[3] Moser, S.C. \& Ekstrom, J.A., A framework to diagnose barriers to climate change adaptation. PNAS, 107(21), pp. 22026-22031, 2010.

[4] Amundsen, H., Berglund, F. \& Westskog, H., Overcoming barriers to climate change adaptation: A question of multilevel governance? Environment and Planning C: Government and Policy, 28, pp. 276-289, 2010.

[5] Biesbroek, G.R., Klostermann, J., Termeer, C. \& Kabat, P., Barriers to climate change adaptation in the Netherlands. Climate Law, 2, pp. 181-199, 2011.

[6] Eisenack, K., Moser, S.C., Hoffmann, E., Klein, R.J.T., Oberlack, C., Pechan, A., Rotter, M., \& Termeer, C.J.A.M., Explaining and overcoming barriers to climate change adaptation. Nature Climate Change, 4, pp. 867$872,2014$.

[7] Uittenbroek, C.J., Janssen-Jansen, L.B. \& Runhaar, H.A.C., Mainstreaming climate adaptation into urban planning: Overcoming barriers, seizing 
opportunities and evaluating the results in two Dutch case studies. Regional Environmental Change, 13, pp. 399-411, 2014.

[8] Ayers, J.M., Huq, S., Faisal, A.M. \& Hussain, S.T., Mainstreaming climate change adaptation into development: A case study of Bangladesh. WIRES Climate Change, 5, pp. 37-51, 2014.

[9] Ayers, J. \& Dodman, D., Climate change adaptation and development I: The state of the debate. Progress in Development Studies, 10(2), pp. 161-168, 2010.

[10] Burch, S., Transforming barriers into enablers of action on climate change: Insights from three municipal case studies in British Columbia, Canada. Global Environmental Change, 20, pp. 287-297, 2010.

[11] Lehmann, P., Brenck, M., Gebhardt, O., Schaller, S., \& Süßbauer, E., Barriers and opportunities for urban adaptation planning: Analytical framework and evidence from cities in Latin America and Germany. Mitigation and Adaptation Strategies for Global Change, 20, pp. 75-97, 2015.

[12] Hamin, E.M., Gurran, N., \& Emlinger, A.M., Barriers to municipal climate adaptation: Examples from coastal Massachusetts' smaller cities and towns. Journal of the American Planning Association 80(2), pp. 110-122, 2014.

[13] Gardner, J., Parsons, R., Paxton, G., Adaptation benchmarking survey: Initial report. Commonwealth Scientific and Industrial Research Organisation: Australia, 2010.

[14] Oberlack, C. \& Eisenack, K., Alleviating barriers to urban climate change adaptation through international cooperation. Global Environmental Change, 24, pp. 349-362, 2014.

[15] PSA, http://web0.psa.gov.ph/content/2010-census-population-and-housing -reveals-philippine-population-9234-million

[16] Lasco, R.D., Pulhin, F.B., Jaranilla-Sanchez, P.A., Delfino, R.J.P., Gerpacio, R., \& Garcia, K., Mainstreaming adaptation in developing countries: The case of the Philippines. Climate and Development, 1, pp. 130-146, 2009.

[17] World Bank, Getting a Grip on Climate Change in the Philippines: Executive Report. The World Bank: Washington, DC, USA, 2013.

[18] CCC, National Climate Change Action Plan: 2011-2028. Climate Change Commission: Manila, Philippines, 2011.

[19] David, C.P.C., Racoma, B.A.B.; Gonzales, J. \& Clutario, M.V., A manifestation of climate change? A look at Typhoon Yolanda in relation to the historical tropical cyclone archive. Science Diliman, 25(2), pp. 78-85, 2013.

[20] NDRRMC. NDRRMC Update: Updates re: The effects of Typhoon "Yolanda" Haiyan. National Disaster Risk Reduction and Management Council, Quezon City, Philippines, 2014.

[21] NSCB, http://www.nscb.gov.ph/activestats/psgc/articles/con_lgu.asp

[22] Claudio, C.P., Climate Change Adaptation Best Practices in the Philippines. Department of Environment and Natural Resources: Manila, Philippines, 2012. 
[23] Salceda, J.S. \& Rangasa, N.C. A model Philippine climate change adaptation initiatives 2011. Local Climate Change Adaptation for Development: Albay, Philippines, 2011.

[24] Ostrom, E., Institutional Rational Choice: An Assessment of the Institutional Analysis and Development Framework. Theories of the Policy Process, Second edition, ed. Sabatier, P.A., Westview Press: Colorado, USA, pp. 2164, 2007.

[25] Agrawala, S., \& van Aalst, M., Bridging the gap between climate change and development. Bridge Over Troubled Waters: Linking Climate Change and Development, ed. S. Agrawala, OECD Publishing: Paris, pp. 133-146, 2006.

[26] Cuevas, S.C., Peterson, A., Morrison, T. \& Robinson, C., Challenges in mainstreaming climate change adaptation into local land use planning: Evidence from Albay, Philippines. The International Journal of Climate Change: Impacts and Responses, Forthcoming.

[27] McGinnis, M., An introduction to IAD and the language of the Ostrom Workshop: A Simple Guide to a Complex Framework. The Policy Studies Journal, 39(1), pp. 169-183, 2011.

[28] Rudd, M.A., An institutional framework for designing and monitoring ecosystem-based fisheries management policy experiments. Ecological Economics, 48, pp. 109-124, 2004.

[29] Ratner, B.D., Meinzen-Dick, R., May, C., Haglund, E., Resource conflict, collective action, and resilience: an analytical framework. International Journal of the Commons, 7(1), pp. 183-208, 2013.

[30] Jones, R., Young, C., Handmer, J., Keating, A., Mekala, G., \& Sheehan, P., Valuing adaptation under rapid change. National Climate Change Adaptation Research Facility, Gold Coast, 2013.

[31] Tearfund, Overcoming the barriers: Mainstreaming climate change adaptation in developing countries. UK, 2006.

[32] Roberts, D., Thinking globally, acting locally - institutionalizing climate change at the local government level in Durban, South Africa. Environment \& Urbanization, 20(2), pp. 521-537, 2008.

[33] Asuero, A.G., Sayago, A. \& González, A.G., The correlation coefficient: an overview. Critical Reviews in Analytical Chemistry, 36(1), pp. 41-59, 2006.

[34] Moutinho, L., Correlation Analysis. The SAGE Dictionary of Quantitative Management Research, ed. L. Moutinho, G. Hutcheson. SAGE Publications Ltd: London, UK, pp. 57-61, 2011.

[35] Tavakol, M. \& Dennick, R., Making sense of Cronbach's alpha. International Journal of Medical Education, 2, pp. 53-55, 2011.

[36] PreventionWeb, http://www.preventionweb.net/english/professional/news/ v.php?id=16235

[37] UNISDR, http://www.unisdr.org/campaign/resilientcities/champions/view/ 47682031

[38] PGA, Provincial Resolution No. 2007-24. Provincial Government of Albay, Albay, Philippines, 2007.

[39] Interviews, 2014. 